\title{
Seek and ye shall find... crossed pulmonary arteries. Comment on crossed pulmonary arteries with hypoplasia of the transverse aortic arch
}

Received: 2 April 2015; Accepted: 2 April 2015; First published online: 9 June 2015

I have read the recent publication on crossed pulmonary arteries ${ }^{1}$ with great interest, and I would like to both cordially thank the authors for bringing up the issue and share a comment on it. Reading the title, I had an impression that I had already seen such a configuration of the pulmonary arteries at least once before. By briefly re-assessing a set of 35 computed tomography angiographies (angio-CT) collected in the last 2 years, it was possible to identify two cases of crossed pulmonary arteries, both of the "lesser form" and also dubbed malposition of the pulmonary branches without crossing. ${ }^{3}$ Moreover, both cases had evidence of the characteristic order of the arteries when observed cranial to caudal: duct or its "diverticulum", left pulmonary branch, and lastly right pulmonary branch. ${ }^{3}$

The first case was a 30-month-old girl with a symptomatic vascular ring, a previously corrected ventricular septal defect, and a small atrial septal defect found to have a persistent left superior caval vein, right-sided aortic arch, and left-sided arterial ligament (Fig 1a-d). The ligament was ligated to

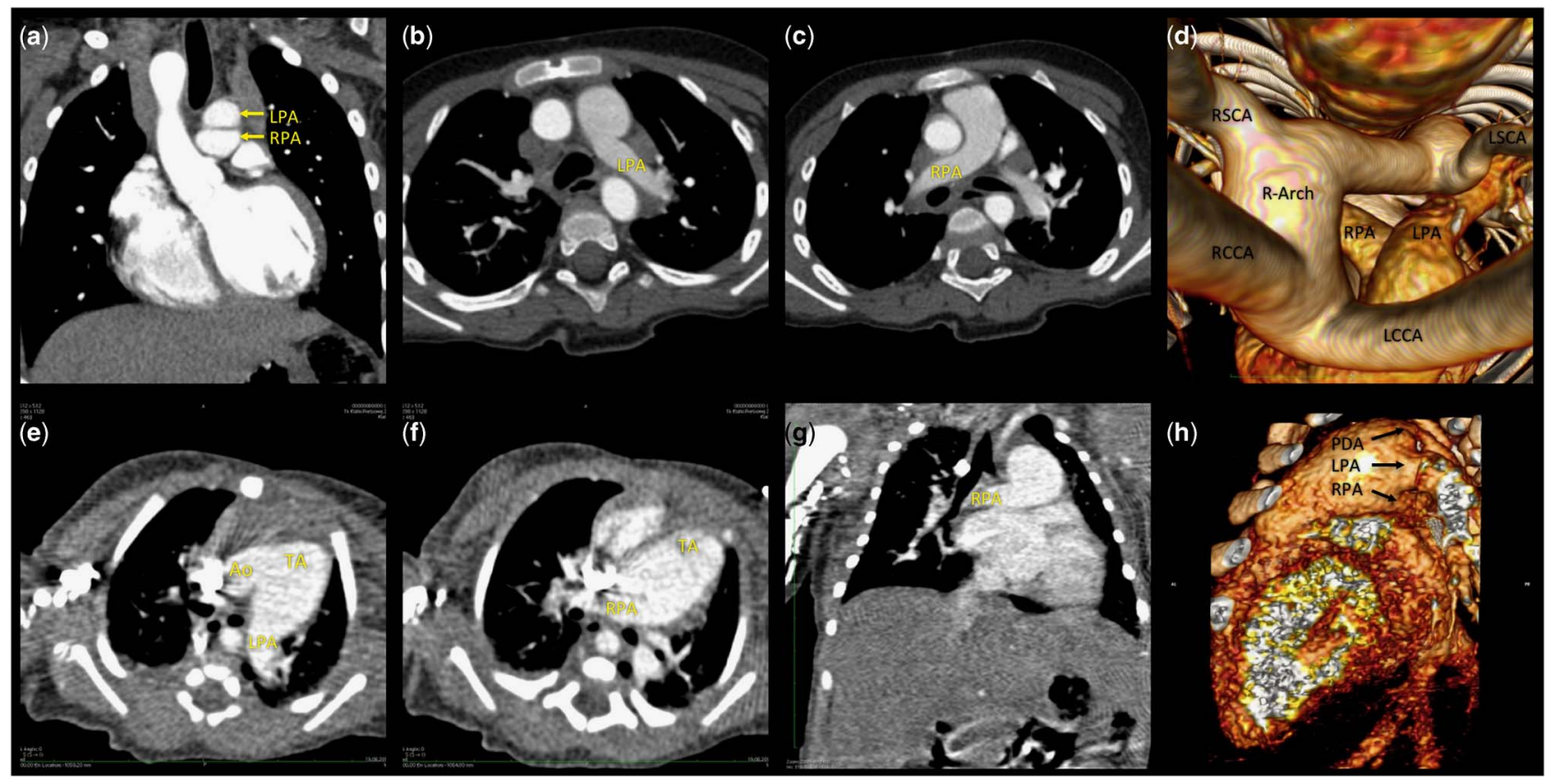

Figure 1.

CT scans - coronal and axial planes and three-dimensional volume rendering - of the two cases with crossed pulmonary arteries and additional defects. $(\boldsymbol{a}-\boldsymbol{d})$ Case 1 - right-sided aortic arch forming a vascular ring. (e-b) Case 2 - truncus arteriosus and interrupted aortic arch. $P D A=$ patent ductus arteriosus; $R C C A / L C C A=$ right/left common carotid artery; $R P A / L P A=$ right/left pulmonary artery; $R S C A$ / LSCA = right/left subclavian artery; TA = truncus arteriosus. The supplementary data available online provide a fly through movie of Case 1.

Correspondence to: J. Meyer-Szary, Department of Pediatric Cardiology and Congenital Heart Diseases, Medical University of Gdańsk, M. Skłodowskiej-Curie 3a, 80-210 Gdańsk, Poland. Tel: +4858 349 2882; Fax: +4858 349 2895; E-mail: jmeyerszary@gumed.edu.pl 
successfully loosen the ring. Cardiovascular abnormalities, frequent infections, thrombocytopaenia, and hypophosphataemia, in spite of normal calcaemia and apparently normal phenotype, raised a suspicion of 22q11 microdeletion.

The other case was an infant with a grave general status, scanned with angio-CT at 2 days of age, diagnosed with double-outflow right ventricle, truncus arteriosus with interrupted aortic arch A4 by Van Praaghs classification, and a small patent arterial duct (Fig 1e-h). The subsequent emergent surgery focused on re-constructing the aortic continuity, ligating the patent arterial duct, and separately banding both the pulmonary branches. The aim was achieved without complications. No extracardiac markers of 22q11 microdeletion were noted.

The author also has an impression that the imagery presented by Cannioto ${ }^{4}$ as double aortic arch may in fact be the third (in total, second chronologically) case of crossed pulmonary arteries with double aortic arch.

The above exemplifies several issues. First, the modern database-driven DICOM storage and viewing solutions such as OsiriX can expedite re-assessment of past examinations as new information or insight arrive. Second, paediatric cardiologists should practice viewing and processing multimodality imaging studies along with radiologists, as some subtle findings may not make it to the report when deemed insignificant even when noticed, plus it is a great way to study the anatomy of CHDs. Most importantly, however, the above confirms two crucial statements made by Hernandez et al. The addition of CT facilitated by three-dimensional volume rendering has improved the chance of detecting rare abnormalities. Finally, maybe crossed pulmonary arteries are not that rare after all, but we have just started to notice and report them; thus, again proving the Matthews verse to be equally true in medicine as in daily life.

\section{Jarostaw Meyer-Szary, Joanna Kwiatkowska Department of Pediatric Cardiology and Congenital Heart Diseases, Medical University of Gdansk Gdańsk, Poland}

\section{References}

1. Hernandez LE, Anderson RH, Hoggard E, St. Louis JD, Shepard CW. Crossed pulmonary arteries with hypoplasia of the transverse aortic arch. Cardiol Young 2015; 25: 718-724.

2. Cuturilo G, Drakulic D, Krstic A, Gradinac M, Ilisic T, Parezanovic V, et al. The role of modern imaging techniques in the diagnosis of malposition of the branch pulmonary arteries and possible association with microdeletion 22q11.2. Cardiol Young 2013; 23: 181-188.

3. Recto MR, Parness IA, Gelb BD, Lopez L, Lai WW. Clinical implications and possible association of malposition of the branch pulmonary arteries with DiGeorge syndrome and microdeletion of chromosomal region 22q11. Am J Cardiol 1997; 80: 1624-1627.

4. Cannioto Z, Ngalikpima CJ, Dall'Amico R. A newborn with double aortic arch. J Pediatr 2013; 163: 917. 